\title{
Current perspectives in HIV post-exposure prophylaxis
}

This article was published in the following Dove Press journal:

HIVIAIDS-Research and Palliative Care

24 October 2014

Number of times this article has been viewed

\section{Binta Sultan ${ }^{1,2}$ \\ Paul Benn' \\ Laura Waters'}

'Department of Genitourinary Medicine, Mortimer Market Centre, Central and North West London NHS Foundation Trust, London, UK; ${ }^{2}$ Centre for Sexual Health and HIV Research, University College London, London, UK
Correspondence: Dr Laura Waters Department of Genitourinary Medicine, Mortimer Market Centre, Capper Street, London WCIE 6JB, UK

Email Iwaters@nhs.net

\begin{abstract}
The incidence of human immunodeficiency virus (HIV) infection continues to rise among core groups and efforts to reduce the numbers of new infections are being redoubled. Post-exposure prophylaxis (PEP) is the use of short-term antiretroviral therapy (ART) to reduce the risk of acquisition of HIV infection following exposure. Current guidelines recommend a 28-day course of ART within 36-72 hours of exposure to HIV. As long as individuals continue to be exposed to HIV there will be a role for PEP in the foreseeable future. Nonoccupational PEP, the vast majority of which is for sexual exposure (PEPSE), has a significant role to play in HIV prevention efforts. Awareness of PEP and its availability for both clinicians and those who are eligible to receive it are crucial to ensure that PEP is used to its full potential in any HIV prevention strategy. In this review, we provide current evidence for the use of PEPSE, assessment of the risk of HIV transmission, indications for PEP, drug regimens, and management of patients started on PEP. We summarize national and international guidelines for the use of PEPSE. We explore the place of PEP within the wider strategy of reducing HIV incidence rates in the era of treatment as prevention and pre-exposure prophylaxis. We also consider the implications of recent data from interventional and observational studies demonstrating significant reductions in the risk of HIV transmission within a serodiscordant relationship if the HIV-positive partner is taking effective ART upon PEP guidelines.
\end{abstract}

Keywords: post-exposure prophylaxis, pre-exposure prophylaxis, treatment as prevention, human immunodeficiency virus

\section{Introduction}

Different strategies for human immunodeficiency virus (HIV) prevention including earlier HIV diagnosis and the use of antiretroviral therapy (ART) to prevent transmission of HIV (treatment as prevention [TasP] and pre- and post-exposure prophylaxis [PrEP and PEP]) are of considerable interest. The Joint United Nations Programme on HIV and AIDS (UNAIDS) declaration on HIV and AIDS in 2011 confirms that HIV prevention must remain the cornerstone of the HIV response. ${ }^{1}$ PEP is the use of short-term ART to reduce the risk of acquisition of HIV infection following exposure. It is widely available following occupational exposure to HIV and has become increasingly available for nonoccupational exposure to HIV.

\section{HIV incidence and prevalence}

The number of people with newly acquired HIV infection continues to rise, with 2.3 million new infections worldwide in $2012 .{ }^{1}$ There is a resurgence of the HIV epidemic among men who have sex with men (MSM) in North America and 
Western Europe. Between 2000 and 2006 there was an 86\% rise in the annual number of new HIV diagnoses in this risk group. ${ }^{1}$ It is essential for HIV prevention efforts to maintain their intensity and that novel ways of preventing HIV infection are incorporated into existing strategies in order to reduce the incidence of HIV infection.

Nonoccupational PEP, the vast majority of which is for sexual exposure (PEPSE), has a role to play in these prevention efforts. This review will focus mainly on PEPSE but can also be applied to any other nonoccupational PEP.

\section{Rationale for PEP}

It may take up to 72 hours for HIV to be detected in regional lymph nodes, up to 5 days to be detected in blood, ${ }^{2,3}$ and about 8 days to be detected in the cerebrospinal fluid. ${ }^{4}$ This offers a window of opportunity to prevent acquisition of HIV infection following exposure ${ }^{5}$ by inhibiting viral replication or preventing dissemination of infection, if ART is started early. ${ }^{6}$

\section{Evidence for PEP}

Much of the data for PEP efficacy comes from animal models. Data from retrospective analyses of PEP for occupational exposure as well as vertical (mother-to-child) transmission studies add to the evidence base for HIV PEP. Based on this data, PEPSE is likely to be effective.

\section{Animal models}

Most animal models have shown benefit of PEP in terms of preventing HIV acquisition. However, comparisons between these studies are difficult as they use different retroviruses, inocula volumes, and modes of transmission.

A recent macaque study of intermittent PrEP and PEP with oral combined tenofovir and emtricitabine (Truvada ${ }^{\circledR}$, Gilead Sciences, Foster City, CA, USA) following rectal inocula demonstrated that a post-exposure dose was essential to prevent infection. ${ }^{7}$ The greatest protection was achieved with the first Truvada dose between 22 hours and 7 days preexposure, with the second dose 2 hours post-exposure.

Other studies have shown that 28 days subcutaneous tenofovir administered to macaques after intravenous ${ }^{8}$ or intravaginal ${ }^{9}$ exposure prevented $100 \%$ of infections if given within 24 or 36 hours, respectively. The proportion of macaques infected increased with: 1) longer intervals to tenofovir administration (no protection if administered 72 hours post-exposure); or 2) decreased duration of treatment. ${ }^{8,9}$

One study showed no protection from triple PEP after intravenous inoculation which may have been due to the inoculum size or route of administration. ${ }^{10}$

\section{Human studies}

\section{Vertical transmission}

Studies illustrating a reduction in vertical transmission of HIV with antiretroviral treatment of pregnant women also support the efficacy of PEP. In AIDS Clinical Trials Group (ACTG) 076 , reduced incidence of HIV was observed in neonates given 6 weeks of zidovudine within 48 hours of delivery to women who had not received any ART prior to delivery. ${ }^{11,12}$ Recent evidence in pregnant women who had not received ART suggests that dual or triple ART for the neonate is more effective than monotherapy in preventing mother-to-child transmission. ${ }^{13}$

\section{Occupational exposure to HIV}

There are no prospective randomized controlled trials of PEP efficacy due to the ethics of withholding a potentially efficacious treatment and the difficulty in recruiting the high number of participants that would be required for such a study.

Much of the rationale for PEP use in humans is derived from a case-control study of health care workers occupationally exposed to HIV, which demonstrated that a 28-day course of zidovudine was protective (odds ratio [OR]: 0.19, 95\% confidence interval $[\mathrm{CI}]: 0.06-0.52) .{ }^{14}$ This study has limitations, including a small number of cases $(n=33)$; also, cases and controls $(n=665)$ were derived from different countries and data on exposure characteristics were collected retrospectively. To date, there are at least 24 cases of PEP failure following occupational exposure, mostly after the use of zidovudine monotherapy. ${ }^{15}$

\section{PEPSE}

There is a paucity of data regarding the efficacy of PEPSE and no randomized controlled trials. An observational PEPSE study undertaken in Brazil among MSM provided with PEP for use after a high-risk exposure demonstrated fewer HIV seroconversions among individuals taking PEPSE compared to those who did not; however, the study also found that people did not estimate their own risk well. When they took PEP, it was effective but the overall HIV incidence remained unchanged compared with historical rates because they did not access PEP after other high-risk episodes. ${ }^{16}$ A recent systematic review of PEPSE concluded that it was not possible to determine its effectiveness due to the lack of evidence, although it may be cost-effective in certain circumstances. ${ }^{17}$

\section{Assessment of the risk of HIV transmission}

Risk of HIV transmission $=$ risk that source is HIV-positive $\times$ risk of exposure*

(*including cofactors such as sexually transmitted infections (STIs), high viral load, and bleeding). 
The decision to initiate PEP should be based upon a risk/benefit analysis weighing up the risk of an individual acquiring HIV and the potential for harm due to PEP. This risk of transmission is determined by the risk that the source is HIV-positive and the type of exposure (Table 1). Risk of HIV transmission is greatest for blood transfusions, followed by vertical exposure, sexual exposures, and other parenteral exposures. Sexual exposure accounts for the majority of HIV infections, with much variability in the risk of acquiring HIV depending on the specific sexual act. The risks from sexual exposure ranged from low for oral sex to 138 infections per 10,000 exposures for receptive anal intercourse. ${ }^{18,19}$ Unprotected receptive anal intercourse (UPRAI) and sharing needles have the highest risk of acquiring HIV per exposure. Insertive anal intercourse (IAI) and vaginal intercourse (receptive and insertive) and oral sex are described as having lower per-act risks.

\section{Anal intercourse}

An Australian cohort study ${ }^{18}$ estimated that the per-contact probability of HIV transmission in MSM through UPRAI was $1.43 \%$ with ejaculation and $0.65 \%$ without ejaculation. The risk through IAI was $0.62 \%$ in uncircumcised men and $0.11 \%$ in circumcised men. A meta-analysis ${ }^{19}$ demonstrated a per-act risk of UPRAI of $1.4 \%$, with no significant difference between heterosexuals and MSMs. They also showed that there was much variability in the risks of anal intercourse, and that it may increase the risk of transmission even when the partner is on ART.

\section{Vaginal intercourse}

A European study estimated the risk of receptive vaginal intercourse to be $0.08 \%$, and insertive vaginal intercourse to be $0.04 \% .^{20}$ This risk is reduced when the partner is on

Table I Risk of HIV transmission per exposure

\begin{tabular}{ll}
\hline Type of exposure & $\begin{array}{l}\text { Estimated median (range) } \\
\text { risk of HIV transmission } \\
\text { per exposure }\end{array}$ \\
\hline Receptive anal intercourse & $1.11 \%(0.042 \%-3.0 \%)$ \\
Insertive anal intercourse & $0.06 \%(0.06 \%-0.065 \%)$ \\
Receptive vaginal intercourse & $0.1 \%(0.004 \%-0.32 \%)$ \\
Insertive vaginal intercourse & $0.082 \%(0.011 \%-0.38 \%)$ \\
Receptive oral sex (fellatio) & $0.02 \%(0 \%-0.04 \%)$ \\
Insertive oral sex (receiving fellatio) & $0 \%$ \\
Blood transfusion (one unit) & $(90 \%-100 \%)$ \\
Needlestick injury & $0.3 \%(95 \% \mathrm{Cl}: 0.2 \%-0.5 \%)$ \\
Sharing injecting equipment & $0.67 \%$ \\
Mucous membrane exposure & $0.63 \%(95 \% \mathrm{Cl}: 0.018 \%-3.47 \%)$ \\
\hline
\end{tabular}

Note: Data are from BASHH Guidelines for PEP. ${ }^{64}$

Abbreviations: $\mathrm{BASHH}$, British Association for Sexual Health and $\mathrm{HIV} ; \mathrm{Cl}$, confidence interval; HIV, human immunodeficiency virus; PEP, post-exposure prophylaxis. effective ART. ${ }^{21}$ Caution should be used in using these estimates as heterosexual infectivity is variable and thought to be underestimated, ${ }^{22}$ and cofactors such as genital ulcer disease have a significant impact on transmission risks.

\section{Oral intercourse}

There has been some observational data that HIV can be transmitted through oral intercourse, but the risks are difficult to estimate, due to the likelihood of other concurrent sexual risk exposures, and are thought to be very low. A study estimated a per-act risk of receptive oral intercourse with ejaculation at $0.06 \%$ with an HIV-positive partner or partner of unknown status, with no increased risk with insertive oral intercourse. ${ }^{23}$

Where the HIV status of the source is unknown, it is important to consider the local HIV prevalence within the relevant risk groups.

\section{The HIV status of the source individual}

The HIV status of the source individual is key to determining the risk of HIV acquisition for the person exposed, and thereby, whether PEP is indicated. It is important that active attempts are made to determine the HIV status and treatment history of the source individual. This is often not possible, particularly in the cases of sexual assault or when casual partners are untraceable. If it is not possible to determine the HIV status of the source, assumptions about their HIV risk must be made based on demographic characteristics, which will vary from region to region. In the UK, MSM and heterosexuals from Sub-Saharan Africa have the greatest likelihood of being HIV-positive ${ }^{24}$ and are considered higher risk individuals.

The risk of HIV transmission is highest in those people who have had blood or mucosal exposure to someone who is HIV-positive and with a detectable viral load. UPRAI remains the highest sexual risk exposure for HIV acquisition. The previously listed cofactors may influence the risk of HIV transmission and should be taken into account when determining whether an individual should receive PEPSE.

Other factors may influence the risk of HIV transmission; these include:

1. High plasma viral load in the source: this may be particularly relevant during primary HIV infection, which accounts for a significant proportion of new infections. ${ }^{25,26} \mathrm{UK}$ guidelines now recommend that the risk of HIV transmission and the protection conferred by effective ART should be discussed with HIV-positive patients - this is highlighted also as a reason to consider starting HIV treatment during primary HIV infection. ${ }^{27}$ Low or undetectable plasma viral loads reduce the risk, 
but transmission may still be possible. Viral loads in the genital tract usually correlate with plasma viral loads, but there can be exceptions and viral suppression in the genital compartment may lag behind plasma. The HIV Prevention Trials Network (HPTN) study ${ }^{21}$ demonstrated that early initiation of ART results in a $96 \%$ relative risk reduction of HIV transmission in serodiscordant couples. Results of the PARTNERS study presented at the Conference on Retroviruses and Opportunistic Infections (CROI), ${ }^{28}$ showed no HIV transmissions to date between serodifferent MSM and heterosexual couples where the HIV-positive partner had an undetectable HIV viral load; the predicted number of transmissions had the partner living with HIV not been treated was 86 .

2. STIs: there is evidence that STIs enhance HIV transmission and increase HIV shedding from the genital tract. ${ }^{29-32}$ This may not be the case in individuals receiving effective ART.

3. Breaches in the mucosal barrier: this includes mouth or genital ulcer disease and trauma. ${ }^{33}$

4. Exposure to blood: menstruation or other bleeding may also facilitate transmission.

5. Ejaculation: the risk of HIV transmission is likely to be greater if ejaculation occurs. Among a community cohort of MSM, the risk of HIV acquisition per episode of UPRAI with and without ejaculation was estimated to be $1.43 \%(95 \% \mathrm{CI}: 0.48-2.85)$ and $0.65 \%(95 \%$ CI: $0.15-1.53)$, respectively. ${ }^{18}$

6. Circumcision: circumcision significantly reduces HIV acquisition among heterosexual men in high prevalence countries. ${ }^{34-36}$ A meta-analysis of observational studies among MSM suggests circumcision may have little impact upon HIV acquisition, as receptive anal intercourse is the key driver of transmission. ${ }^{37}$ However, there may be benefit for MSMs who exclusively or almost exclusively practice IAI. An Australian cohort ${ }^{18}$ showed a reduction in per-act risk of HIV transmission from $0.62 \%$ in uncircumcised MSM to $0.11 \%$ in circumcised MSM. Data from observational studies suggest a $73 \%$ relative risk reduction for men who are circumcised and practice mainly IAI. ${ }^{38}$

\section{Factors that influence the efficacy of PEP}

Individuals have acquired HIV following both occupational and sexual exposures, despite the use of PEP. Therefore, PEP is not $100 \%$ effective.
Various factors that influence PEP effectiveness include:

- Time to starting PEP

- Incomplete adherence/non-completion

- Source virus

- Penetration of drugs into tissue compartments

- Further high-risk sexual exposures

\section{Time to starting PEP}

PEP is likely to be ineffective if initiated more than 72 hours after exposure; the majority of international guidelines do not recommend PEP provision after this time, and other guidelines recommend even shorter window periods. New York State guidelines recommend nonoccupational PEP is given no more than 36 hours after exposure. ${ }^{39}$ This discrepancy exists as there has have been no prospective trials in humans to assess the optimal time for commencement of PEP after an exposure. However, the data from animal studies ${ }^{3,8,9}$ provide strong evidence of increasing rates of failure of PEP by 48-72 hours after exposure.

One animal study showed that when time to treatment was extended to 48 and 72 hours post-exposure, half the animals in both groups were persistently infected. ${ }^{8}$

Another study investigated 28 days of tenofovir started at different post-exposure intervals in vaginally exposed macaques; ${ }^{40}$ only one seroconversion in an animal started on PEP 72 hours post-exposure was found compared to none in the 24- and 48-hour post-exposure groups; this was a statistically significant finding (Fisher's exact test, $P=0.018$ ).

Occupational guidelines recommend that PEP is commenced as soon as possible after the exposure. ${ }^{41}$ The time to initiating PEPSE is often longer than for occupational exposure. ${ }^{17}$ This may be as a consequence of both delays in patients seeking PEP as well as the provision of PEP by health care professionals.

\section{Adherence to PEP}

Adherence and completion rates of 4 weeks of PEP among health care workers and individuals exposed nonoccupationally are often poor, which may impact upon its efficacy. ${ }^{42-46}$ Pill burden and the side effects of treatment may influence completion rates. Other factors such as psychological distress and re-evaluation of risk may also impact PEP completion.

A recent systematic review of PEP use in victims of sexual assault showed poor adherence, with better completion rates in developing countries. ${ }^{47}$ Unmeasured factors such as stigma associated with sexual assault may play a role in this. 
However, in a recent meta-analysis of PEP in non-forcible exposure to HIV, taking into account those that were lost to follow-up, found that $67 \%$ of people completed a 28 -day course of PEP. This was higher in groups that had counseling throughout the course of treatment. ${ }^{48}$ Psychological and social support are important adjuncts to effective PEP services.

\section{Drug resistance in the source}

PEP efficacy may be compromised if the source has a virus that is resistant to one of the agents used. ${ }^{49}$ The prevalence of antiretroviral resistance among those with primary HIV infection and those chronically infected with HIV has plateaued at $8 \%$ in the UK and Europe, ${ }^{50,51}$ but this is not the case in low- and middle-income countries. A meta-analysis has demonstrated a significant increase in the prevalence of drug resistance over time since antiretroviral rollout in regions of Sub-Saharan Africa. ${ }^{52}$ If the source is known or suspected to have drug resistance, the PEP regimen should be tailored accordingly.

\section{Drug penetration into tissue compartments}

There is evidence that, even with optimal viral suppression in the blood, HIV can be detected in other tissue compartments. ${ }^{53}$ As different antiretroviral agents penetrate these compartments to different degrees, ${ }^{54}$ the choice of drugs used in PEP could influence its efficacy.

\section{Risks of PEP}

The risks of starting PEP are summarized below:

1. Drug side effects: all ART can cause side effects, which should be considered carefully and discussed before starting PEP. ${ }^{55}$ Symptoms, such as diarrhea, are one of the main reasons for nonadherence and discontinuation of PEP. Drug side effects are discussed further in the section describing the various antiretroviral options for PEP.

2. Behavioral and psychological implications: despite concerns that PEPSE and PrEP availability will reduce individual commitment to other primary prevention strategies, such as condoms and behavioral interventions, ${ }^{56,57}$ there is little evidence of increased risk behavior among individuals with access to $\mathrm{PEP}^{58,59}$ and in a large randomized trial of PrEP, there was a reduction in risky behavior. ${ }^{60}$ The impact of open-label PrEP use upon risk compensation has yet to be determined. The availability of PEPSE in clinics provides an opportunity to offer health education, health promotion, risk reduction strategies, and HIV prevention strategies such as PrEP to high-risk individuals who may not access services otherwise.
3. Drug resistance: there is a potential risk of drug resistance developing in those who fail to complete PEP and acquire HIV. Poor adherence was a risk for subsequent seroconversion in a retrospective analysis of PEPSE failures. ${ }^{46}$ It is likely that adherence and treatment completion rates will be better with more tolerable PEP regimens.

\section{Choice of ART}

The choice of drugs to be used for PEP is based on those used to treat established HIV infection.

For HIV therapy, combination drug therapy with at least three drugs is more effective than single drug regimens. Consensus guidelines for chronic HIV infection recommend three drugs from at least two drug classes (typically two nucleoside reverse transcriptase inhibitors [NRTI] with a nonnucleoside reverse transcriptase inhibitor [NNRTI], a boosted protease inhibitor $[\mathrm{PI} / \mathrm{r}]$, or an integrase inhibitor [INI]). Most PEPSE guidelines recommend three drugs for PEPSE based upon the evidence for treating HIV-positive individuals and that late presentation for PEP and the potential for drug resistance in the source make triple therapy likely to be more effective than mono- or dual-therapy PEP.

A recent study has been the first to effectively demonstrate that a two or three drug regimen is more effective than monotherapy for nonoccupational PEP. ${ }^{13}$ This study also showed that dual therapy can be as effective as triple therapy, with no difference in efficacy seen. The cost benefit of adding in a third drug should be considered, but this is a decision that needs to be made in the context of the individual patient, their risks, and the risk of the source. Almost all guidelines advise a triple therapy regimen. Expert advice should be sought if the source is known or suspected to have viral resistance.

\section{NRTI}

Zidovudine (an NRTI) is the only drug to date for which there is evidence of reduced HIV transmission risk following occupational exposure. Combivir ${ }^{\circledR}$ (GlaxoSmithKline plc, London, UK), a fixed dose combination of zidovudine and lamivudine (another NRTI) was frequently used for PEP. Combivir is commonly associated with side effects, particularly gastrointestinal, which may contribute to poor adherence. The routine use of abacavir is not recommended. A hypersensitivity reaction is reported in up to $8 \%$ of patients with established infection. ${ }^{61,62}$

Truvada (a fixed dose combination of tenofovir disoproxil fumarate [TDF] and emtricitabine [FTC]; Gilead Sciences) is better tolerated than Combivir with fewer side effects, so is often a first choice PEP component. Both TDF and FTC 
penetrate the genital tract and rectal tissue well in animal models. ${ }^{7}$ Truvada has been shown to significantly reduce acquisition of HIV when used as PrEP in MSM, ${ }^{60}$ although studies in heterosexuals are conflicting. ${ }^{63-66}$

\section{NNRTIs}

Nevirapine has been associated with significant toxicity (particularly hepatic) as PEP and is not recommended. ${ }^{55,67}$ Efavirenz has a lower incidence of hepatic and cutaneous toxicity, but as it may be associated with significant central nervous system disturbance, it is not an ideal choice for PEP.

Newer NNRTIs, etravirine and rilpivirine, are welltolerated, although rash is common on etravirine and there have been case reports of severe rash in HIV-positive individuals. ${ }^{68}$ Rilpivirine causes rash less commonly and is currently being evaluated as PEP. ${ }^{69}$

\section{Protease inhibitors}

It is likely that PEP is aborting and inhibiting replication and dissemination rather than preventing infection and that part of this activity will be achieved by rendering new virions noninfective. Therefore, although PI/rs act at a post-integrational stage of the HIV life cycle, they should still provide benefit as PEP.

Nelfinavir, lopinavir/ritonavir (LPV/r), atazanavir/ritonavir (ATV/r), and more recently darunavir/ritonavir ${ }^{70}$ have all been used or evaluated as PEP.

PIs have been associated with metabolic abnormalities as well as gastrointestinal side effects. Kaletra ${ }^{\circledR}$ (Abbott Laboratories, Abbott Park, IL, USA), a fixed dose combination of $\mathrm{LPV} / \mathrm{r}$ is the recommended PI for inclusion with PEP regimens in the $\mathrm{UK},{ }^{71,72}$ but commonly causes diarrhea. ${ }^{73}$

Although newer PIs have better gastrointestinal tolerability than LPV/r in treatment trials, a recent randomized comparison of ATV/r versus Kaletra-based PEP, ${ }^{73}$ each with Combivir, revealed similar and high discontinuation rates $(36 \%$ in each arm) and similar discontinuation rates secondary to PI side effects (16\% due to LPV/r and $17 \%$ due to ATV/r). An Australian study compared PI-based PEP (Combivir plus nelfinavir - an unboosted PI no longer routinely used) with a triple NRTI combination (TDF, lamivudine, and stavudine). ${ }^{74}$ Although the triple NRTI regimen was more frequently associated with peripheral neuropathy and transaminitis, discontinuations were significantly less frequent than on PI-based PEP.

There is also an increased risk of drug-drug interactions with the use of PIs. A recent PEP study found that almost half of the participants were regularly taking at least one prescribed medication. These included corticosteroids, anticonvulsants, antidepressants, anti-lipids, and antihypertensives, which are known to have potential drug interactions with PIs. ${ }^{75}$ It is important to consider drug-drug interactions with prescribed and nonprescribed drugs, including recreational drugs when selecting the best PEP regimen.

\section{Other drug classes}

Raltegravir (RAL), an INI, has a favorable tolerability, safety, and metabolic profile, ${ }^{76}$ and is well-tolerated as PEP. ${ }^{75,77}$ It acts before viral integration and thus may be more effective at preventing HIV infection. It has fewer side effects and fewer drug-drug interactions than other classes of antiretroviral medications. The New York State Department of Health recently started using RAL, FTC, TDF as its first-line occupational and nonoccupational PEP regimen, and the Center for Disease Control (CDC) now recommends the use of RAL for occupational PEP. ${ }^{78} \mathrm{~A}$ recent interventional study assessed RAL as part of a triple drug PEP regimen, including $\mathrm{FTC}$ and TDF, in comparison to FTC and TDF. ${ }^{75}$ Researchers found the RAL regimen had a high completion rate, was effective, and avoided potential drug-drug interactions. However, there was a small risk of acute muscle toxicity. Two other INIs, elvitegravir and dolutegravir, have been licensed recently. Elvitegravir is currently being evaluated as PEP in a study in the US using Stribild ${ }^{\circledR}$ (elvitegravir/cobicistat/emtricitabine/TDF; Gilead Sciences); however, cobicistat has similar drug-drug interactions as ritonavir. ${ }^{79}$

Maraviroc (MVC), the only licensed CCR5 antagonist, also performs well from the perspectives of safety and tolerability. ${ }^{80} \mathrm{HIV}$ can use one of two co-receptors, CCR5 or CXCR4, to enter host cells. Although MVC only inhibits CCR5, there is evidence that the majority of transmitted HIV uses this co-receptor, indicating MVC could be a useful PEP option. Studies investigating MVC as PEP and PrEP options are ongoing. ${ }^{81,82}$ There is also evidence that both RAL and MVC penetrate the genital tract and rectal mucosa well; ${ }^{83-87}$ this may be an important consideration for PEP. More data is required as to their efficacy, although, consistent with national guidance, many centers use RAL for PEP cases where drug-drug interactions or tolerability problems preclude the use of LPV/r. Considerations include resistance and cost-effectiveness.

The UK British Association for Sexual Health and HIV

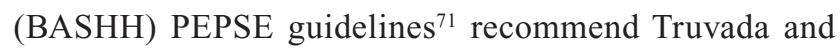
Kaletra for 28 days (Table 2 ) but are currently being reviewed. The guidelines also make recommendations for alternative agents in the event of intolerance, drug-drug interactions, or resistance in the source. US guidelines for nonoccupational 
PEP prefer TDF, lamivudine, and RAL; LPV/r; or EFV with 3/FTC, and list several regimens as alternatives. ${ }^{88}$

\section{Side effects and toxicity}

As aforementioned, antiretrovirals may be associated with side effects and in some cases are tolerated less well by HIVnegative individuals. Symptomatic management may improve tolerability of PEP, and most clinics offer antiemetics and antidiarrheal medications with PEP starter packs. Proximal renal tubular dysfunction and Fanconi's syndrome have been reported in HIV-positive patients receiving tenofovir; although this has not yet been reported in the setting of Truvada use as PEP or PrEP, ${ }^{89,90,91}$ monitoring is still required (Table 3 ).

PEP follow-up data from 140 patients in Brighton, UK, showed $7.1 \%$ developed new blood abnormalities. All except one, showed grade 1 or 2 elevation in alanine transaminase (ALT), one had a grade 3 elevation of ALT (but had a history of excess alcohol use). There have been no reports of Fanconi's syndrome to date in these patients. ${ }^{92}$ Recent data from a clinic in London showed $13 \%$ of people had significant abnormalities

Table 2 Recommended combinations for PEP according to the $\mathrm{BASHH}$ guidelines $20 \mathrm{II}$

Recommended combination

Alternative nucleoside analogs

Alternative protease inhibitors

Alternative to protease inhibitors, eg, in cases with significant drug-drug interactions

\begin{abstract}
Truvada $^{\circledR}$ (TDF plus FTC) one tablet once daily ${ }^{\mathrm{a}}$

and

Kaletra ${ }^{\circledR b, c}$ (ritonavir and lopinavir) two tablets twice daily or four tablets once daily for 28 days Stavudine 30 or $40 \mathrm{mg}$ twice daily (according to weight) or Zidovudine $250 \mathrm{mg}$ twice daily plus

Emtricitabine $200 \mathrm{mg}$ once daily or Lamivudine $300 \mathrm{mg}$ once daily Atazanavir $300 \mathrm{mg}$ once daily plus Ritonavir $100 \mathrm{mg}$ once daily or Darunavir $800 \mathrm{mg}$ once daily plus Ritonavir $100 \mathrm{mg}$ once daily Stavudine 30 or $40 \mathrm{mg}$ twice daily (according to weight) or

Zidovudine $250 \mathrm{mg}$ twice daily or

Raltegravir $400 \mathrm{mg}$ twice daily
\end{abstract}

Notes: ${ }^{a}$ Truvada ${ }^{\circledR}$ is the preferred agent due to pharmacokinetic considerations, tolerability and the evidence base of efficacy based on animal models for the components, ie, TDF and FTC; bAlternative protease inhibitors; 'Alternative to protease inhibitors; 'available as Combivir ${ }^{\circledast}$ (GlaxoSmithKline plc, London, UK), one tablet twice daily. Kaletra ${ }^{\circledR}$, Abbott Laboratories, Abbott Park, IL, USA; Truvada ${ }^{\circledR}$ Gilead Sciences, Foster City, CA, USA. Data are from BASHH PEP guidelines. ${ }^{64}$ Abbreviations: BASHH, British Association for Sexual Health and HIV; FTC, emtricitabine; PEP, post-exposure prophylaxis; TDF, tenofovir disoproxil fumarate.
Table 3 UK PEP monitoring recommendations

\begin{tabular}{llll}
\hline & Baseline & Days 3-28 & Day 42 \\
\hline FBC (if appropriate) & $\sqrt{ }$ & $\sqrt{ }$ & - \\
Renal profile & $\sqrt{ }$ & $\sqrt{ }$ & - \\
Liver function & $\sqrt{ }$ & $\sqrt{ }$ & - \\
Glucose & $\sqrt{ }$ & $\sqrt{ }$ & - \\
Lipids & $\sqrt{ }$ & $\sqrt{ }$ & - \\
Urine dipstick/uPCR & $\sqrt{ }$ & $\sqrt{ }$ & - \\
PT & $\sqrt{ }$ & \pm & - \\
Hepatitis B & $\sqrt{ }$ & - & $\sqrt{ }$ \\
Syphilis & $\sqrt{ }$ & - & $\sqrt{ }$ \\
\hline
\end{tabular}

Note: Data are from BASHH PEP guidelines. ${ }^{64}$

Abbreviations: FBC, full blood count; PEP, post-exposure prophylaxis; PT, prothrombin time; uPCR, urine protein/creatinine; $\sqrt{ }$, recommended; -, not recommended; \pm , is indicated.

at a median onset of 6 days (range $0-28$ days). ${ }^{93}$ This evidence supports regular monitoring throughout the course of PEP in order to detect these abnormalities, consistent with guidelines. ${ }^{71}$ The majority of these biochemical abnormalities normalize on stopping PEP, and require no further follow-up.

\section{Duration of treatment}

The optimal duration of PEP is unknown and there have not been any randomized controlled trials assessing the effectiveness of PEP with suboptimal adherence to the regimen. There have been small animal studies that have suggested 28 days is optimal ${ }^{8}$ and a case-control study of health care workers ${ }^{14}$ showed failure of PEP when the 28 days of treatment was not completed. Therefore, current guidelines recommend that 4 weeks of PEP should be used.

\section{Potential for drug-drug interactions}

It is essential to ensure that the potential for drug-drug interactions is considered with the use of PEP. Clinicians are advised to liaise with an HIV specialist pharmacist and/or use online tools such as http://www.hiv-druginteractions.org/ for this purpose. Individuals should also be warned about interactions with over-the-counter and recreational drugs.

\section{Current guidelines for PEPSE}

Guidelines for starting PEPSE differ by region and are compared in Table 4. UK and US guidelines advise starting PEP before 72 hours of exposure, whereas the European AIDS Clinical Society (EACS) advises starting before 48 hours of exposure. ${ }^{71,77,87,94}$ These guidelines recommend the use of PEPSE following unprotected anal or vaginal sex with someone known or likely to have HIV. The recently updated UK BASHH guidelines ${ }^{71}$ recommend that PEPSE is: 1) indicated when the estimated transmission risk is 1 in 1,000 or greater; 2) considered when the estimated transmission risk is between 
$1 / 1,000$ and 1/10,000; and 3) not recommended when the risk is below $1 / 10,000 .^{71}$ The risk thresholds are similar to those used within the Australian guidelines ${ }^{95}$ and largely reflect where PEPSE may be cost-effective. ART resulted in a significant reduction in HIV transmission among serodiscordant partners in the HPTN 052 study, ${ }^{21}$ and therefore, the UK guidelines do not recommend PEPSE following most sexual exposures where the source's plasma HIV viral load is known to be undetectable with the exception of UPRAI. UPRAI is still included within the recommend category, as this is the major route of HIV transmission in the UK. ${ }^{71}$

The Australian PEP guidelines, however, recommend two drugs following receptive anal intercourse or IAI (uncircumcised) where the source's viral load is undetectable. The difference in recommendations is likely to result from the lack of data of the effect of ART upon sexual transmission among MSM. ${ }^{95}$

All guidelines advise regular follow-up for the evaluation of side effects and adherence to therapy as well as initial and follow-up HIV and hepatitis testing.

We recommend clinicians to broadly follow their own national or regional guidelines for PEP provision. In our view, three drugs remain the gold standard, but in the event of significant toxicity, treatment-limiting intolerability, or difficult drug-drug interactions, then dual-PEP with two NRTI is an acceptable option. Due to better tolerability and fewer drug interactions, we believe that RAL should replace Kaletra as the third agent of choice in our national guidelines; anecdotally, several clinics in the UK have already switched to RAL-based PEP as the first-choice regimen. Finally, the PARTNER Study demonstrated no phylogenetically linked HIV transmission with condomless sex among 282 serodiscordant MSM couples, where the HIV-positive partner was on ART and had a viral load less than 200 copies. ${ }^{19}$ This raises the question of whether PEP is ever required where the positive partner has a suppressed viral load, regardless of the nature of sexual exposure. We believe that where one can be confident that the source of exposure has had an undetectable viral load for at least 6 months, in the context of good adherence, PEP is not indicated for insertive or receptive sexual exposures in the absence of additional risk factors increasing the likelihood of transmission.

\section{Evaluation of patients presenting for PEP}

All patients who present for PEP should have evaluation of the following:

1. determination of HIV status of person presenting for PEP before starting PEP and 3 months after completion of PEP; 
2. timing and frequency of exposure;

3. HIV status of source;

4. transmission risk from the exposure;

5. evaluation for sexually transmitted infections, hepatitis, and emergency contraception at initial presentation and during follow-up period;

6. advice regarding safer sex and risk reduction strategies;

7. follow-up to evaluate adherence and side effects of medication.

PEPSE provides one aspect of a larger HIV prevention strategy and should be provided in the context of other preventative measures, including promotion of condom use, counseling, and support around behavior modification in order to reduce future risk.

Awareness of PEP and its availability for both clinicians and those who are eligible to receive it are crucial to ensure that PEP is used to its full potential in any HIV prevention strategy. A recent study among an HIV-positive cohort in London showed that there was only $50 \%$ awareness of the availability of PEP overall, and $64 \%$ in those who had a detectable HIV viral load. ${ }^{96}$ Data from the CDC assessing HIV providers' prescription of PEPSE in two US districts for their patients were poor, with $59.7 \%$ and $39.3 \%$ having ever prescribed PEPSE. ${ }^{97}$

The decision to start PEP should be made on a case-by-case basis, addressing the unique risks and benefits for each patient. This should consider the risk of transmission according to exposure and the likelihood of the source being HIV-positive as well as the potential for harm as a result of PEPSE.

The indications for provision of PEPSE will continue to be debated but there will be increasingly more discussion about the efficacy and availability of PrEP. ${ }^{56,60}$ This could potentially provide another tool in the strategy of HIV prevention, but further evidence is required and there are ongoing clinical trials to determine the safety and effectiveness of this strategy among different groups. In the meantime, PEPSE is a useful tool in ongoing efforts to reduce the incidence of HIV infection, particularly among risk groups.

\section{Combination prevention strategies}

Increasingly, the place of PEP lies within a wider combination of prevention strategies, which include biomedical, structural, and behavioral interventions to prevent HIV infection ${ }^{98}$ and address the interacting causes of HIV risk and vulnerability. These should be tailored to the local needs of the population and include PEP, PreP, TasP, and risk behavioral interventions such as condom use. HIV prevention and treatment strategies are interdependent. The failure to focus on those with the greatest risk, to focus resources on primary transmission of HIV, and a lack of structural interventions that focus on the causes of vulnerability has already led to rising rates of HIV infection and will likely continue to do so.

PrEP is another drug-based HIV prevention strategy that has been shown to decrease the risk of HIV acquisition in some trials but not others. iPrEx (Pre-exposure Prophylaxis Initiative), a trial of oral Truvada as PrEP in MSM, demonstrated a 44\% reduction in HIV incidence in MSM who were taking PrEP compared to control subjects. ${ }^{60}$ The study demonstrated that those who were adherent, based on measured drug levels, had a greater risk reduction, and therefore greater efficacy of PrEP if used as it is prescribed. However, consideration to the cost, feasibility, and the potential for risk compensation behaviors need to be given. ${ }^{99}$

TasP utilizes the fact that suppressed plasma viremia is strongly correlated with a significant reduction in HIV infectiousness. This has been shown to be highly effective at an individual level: the HPTN 052 trial demonstrated a significant $(96 \%)$ reduction in linked HIV transmissions among the couples where the HIV-positive partner was randomized to immediate, as compared to deferred, ART. ${ }^{21}$ Data on whether effective HIV therapy and the consequent fall in "community viral load" reduces HIV incidence, have been conflicting. This is likely to result from the disproportionate number of new HIV infections arising from individuals with undiagnosed or primary (therefore untreated) HIV in some epidemics (such as the UK). It is likely that we will need to focus on several factors to reduce new HIV infections, including: reducing the burden of undiagnosed HIV infection, educating patients and clinicians to recognize the symptoms of primary HIV, and starting ART in those who wish to in order to reduce the risk of them transmitting to partners.

Falling rates of HIV infection have been linked to changes in behavioral and societal norms. ${ }^{100}$ However, there are still two new infections for every person who is started on HIV treatment. PEP is an important component of prevention strategies, and its role as a public health strategy will evolve as other prevention measures such as PrEP and TasP become more widely available. As long as individuals continue to be exposed to HIV, there will be a role for timely PEP.

\section{Disclosure}

Paul Benn now works for Gilead Sciences Ltd, UK as a Senior Medical Project Manager in HIV. His contributions to this paper were made while still working as an HIV Consultant at the Mortimer Market Centre. The other authors report no conflicts of interest in this work. 


\section{References}

1. Joint United Nations Programme on HIV/AIDS (UNAIDS). Global report: UNAIDS report on the global AIDS epidemic 2013. Geneva, Switzerland: UNAIDS; 2013. Available from: http://www.unaids.org/ en/media/unaids/contentassets/documents/epidemiology/2013/gr2013/ UNAIDS_Global_Report_2013_en.pdf. Accessed December 26, 2013.

2. Pinto LA, Landay AL, Berzofsky JA, Kessler HA, Shearer GM. Immune response to human immunodeficiency virus (HIV) in health care workers occupationally exposed to HIV-contaminated blood. Am J Med. 1997;102(5B):21-24.

3. Spira AI, Marx PA, Patterson BK, et al. Cellular targets of infection and route of viral dissemination after an intravaginal inoculation of simian immunodeficiency virus into rhesus macaques. J Exp Med. 1996;183(1): 215-225.

4. Valcour V, Chalermchai T, Sailasuta N, et al; RV254/SEARCH 010 Study Group. Central nervous system viral invasion and inflammation during acute HIV infection. J Infect Dis. 2012;206(2):275-282.

5. Miller RJ, Cairns JS, Bridges S, Sarver N. Human immunodeficiency virus and AIDS: insights from animal lentiviruses. JVirol. 2000;74(16): 7187-7195.

6. Bourry O, Mannioui A, Sellier P, et al. Effect of a short-term HAART on SIV load in macaque tissues is dependent on time of initiation and antiviral diffusion. Retrovirology. 2010;7:78.

7. García-Lerma JG, Cong ME, Mitchell J, et al. Intermittent prophylaxis with oral truvada protects macaques from rectal SHIV infection. Sci Transl Med. 2010;2(14):14ra4.

8. Tsai CC, Emau P, Follis KE, et al. Effectiveness of postinoculation (R)-9-(2-phosphonylmethoxypropyl) adenine treatment for prevention of persistent simian immunodeficiency virus SIVmne infection depends critically on timing of initiation and duration of treatment. J Virol. 1998;72(5):4265-4273.

9. Otten RA, Smith DK, Adams DR, et al. Efficacy of postexposure prophylaxis after intravaginal exposure of pig-tailed macaques to a human-derived retrovirus (human immunodeficiency virus type 2). J Virol. 2000;74(20):9771-9775.

10. Le Grand R, Vaslin B, Larghero L, et al. Post-exposure prophylaxis with highly active antiretroviral therapy could not protect macaques from infection with SIV/HIV chimera. AIDS. 2000;14(12):1846-1866.

11. Sperling RS, Shapiro DE, Coombs RW, et al. Maternal viral load, zidovudine treatment, and the risk of transmission of human immunodeficiency virus type 1 from mother to infant. Pediatric AIDS Clinical Trials Group Protocol 076 Study Group. N Engl J Med. 1996;335(22):1621-1629.

12. Wade NA, Birkhead GC, Warren BL, et al. Abbreviated regimens of zidovudine prophylaxis and perinatal transmission of the human immunodeficiency virus. N Engl J Med. 1998;339(20):1409-1414.

13. Nielsen-Saines K, Watts DH, Veloso VG, et al; NICHD HPTN 040/PACTG 1043 Protocol Team. Three postpartum antiretroviral regimens to prevent intrapartum HIV infection. N Engl J Med. 2012;366(25): 2368-2379.

14. Cardo DM, Culver DH, Ciesielski CA, et al. A case-control study of HIV seroconversion in health care workers after percutaneous exposure. Centers for Disease Control and Prevention Needlestick Surveillance Group. N Engl J Med. 1997;337(21):1485-1490.

15. Tomkins S, Ncube F. Occupationally acquired HIV: international reports to Dec 2002. Euro Surveill. 2005;10(3):E050310.2.

16. Schechter M, do Lago RF, Mendelsohn AB, et al. Behavioral impact, acceptability, and HIV incidence among homosexual men with access to postexposure chemoprophylaxis for HIV. J Acquir Immune Defic Syndr. 2004;35(5):519-525.

17. Bryant J, Baxter L, Hird S. Non-occupational postexposure prophylaxis for HIV: a systematic review. Health Technol Assess. 2009;13(14):iii, ix $-\mathrm{x}, 1-60$.

18. Jin F, Jansson J, Law M, et al. Per-contact probability of HIV transmission in homosexual men in Sydney in the era of HAART. AIDS. 2010;24(6):907-913.

19. Baggaley RF, White RG, Boily MC. HIV transmission risk through anal intercourse: systematic review, meta-analysis and implications for HIV prevention. Int J Epidemiol. 2010;39(4):1048-1063.
20. Mastro TD, de Vincenzi I. Probabilities of sexual HIV-1 transmission. AIDS. 1996;10 Suppl A:S75-S82.

21. Cohen MS, Ying CQ, McCauley M, et al; HPTN 052 Study Team. Prevention of HIV-1 infection with early antiretroviral therapy. NEngl J Med. 2011;365(6):493-505.

22. Powers KA, Poole C, Pettifor AE, Cohen MS. Rethinking the heterosexual infectivity of HIV-1: a systematic review and meta-analysis. Lancet Infect Dis. 2008;8(9):553-563.

23. VitinghoffE, Douglas J, Judson F, McKirnanD, MacQueen K, Buchbinder SP. Per-contact risk of human immunodeficiency virus transmission between male sexual partners. Am J Epid. 1999;150(3):306-311.

24. Aghaizu A, Brown AE, Nardone A, et al. HIV in the United Kingdom 2013 Report: data to end 2012. London, UK: Public Health England; 2013. Available at: http://www.hpa.org.uk/webc/HPAwebFile/ HPAweb_C/1317140300680. Accessed January 3, 2014.

25. Powers KA, Ghani AC, Miller WC, et al. The role of acute and early HIV infection in the spread of HIV and implications for transmission prevention strategies in Lilongwe, Malawi: a modelling study. Lancet. 2011;378(9787):256-268.

26. Miller WC, Rosenberg NE, Rutstein SE, Powers KA. Role of acute and early HIV infection in the sexual transmission of HIV. Curr Opin HIV AIDS. 2010;5(4):277-282.

27. Writing Group, Williams I, Churchill D, et al. British HIV Association guidelines for the treatment of HIV-1-positive adults with antiretroviral therapy 2012 (Updated Nov 2013. All changed text is cast in yellow highlight.). HIV Med. Jan 2014;15 Suppl 1:1-85.

28. Rodger A, Bruun T, Cambiano V, et al. HIV transmission risk through condomless sex if HIV+ partner on suppressive ART: PARTNER Study. Presented at: 21 st Conference on Retroviruses and Opportunistic Infections (CROI) 2014; March 3-6, 2014; Boston, MA. Abstract \#153LB.

29. Røttingen JA, Cameron DW, Garnett GP. A systematic review of the epidemiologic interactions between classic sexually transmitted diseases and HIV: how much really is known? Sex Transm Dis. 2001;28(10): 579-597.

30. Hayes R, Mosha F, Nicoll A, et al. A community trial of the impact of improved sexually transmitted disease treatment on the HIV epidemic in rural Tanzania: 1. Design. AIDS. 1995;9(8):916-926.

31. Grosskurth H, Mosha F, Todd J, et al. Impact of improved treatment of sexually transmitted diseases on HIV infection in rural Tanzania: randomised controlled trial. Lancet. 1995;346(8974): 530-536.

32. Cohen MS, Hoffmann IF, Royce RA, et al. Reduction of concentration of HIV-1 in semen after treatment of urethritis: implications for prevention of sexual transmission of HIV-1. AIDSCAP Malawi Research Group. Lancet. 1997;349(9069):1868-1873.

33. Rothenberg RB, Scarlett M, del Rio C, Reznik D, O’Daniels C. Oral transmission of HIV. AIDS. 1998;12(16):2095-2105.

34. Auvert B, Taljaard D, Lagarde E, et al. Randomized, controlled intervention trial of male circumcision for reduction of HIV infection risk: the ANRS 1265 Trial. PLoS Med. 2005;2(11):e298.

35. Bailey RC, Moses S, Parker CB, et al. Male circumcision for HIV prevention in young men in Kisumu, Kenya: a randomised controlled trial. Lancet. 2007;369(9562):643-656.

36. Gray RH, Kigozi G, Serwadda D, et al. Male circumcision for HIV prevention in men in Rakai, Uganda: a randomised trial. Lancet. 2007;369(9562):657-666.

37. Millett GA, Flores SA, Marks G, Reed JB, Herbst JH. Circumcision status and risk of HIV and sexually transmitted infections among men who have sex with men: a meta-analysis. JAMA. 2008;300(14): 1674-1684. Erratum in: JAMA. 2009;301(11):1126-1129.

38. Wiysonge CS, Kongnyuy EJ, Shey M, et al. Male circumcision for prevention of homosexual acquisition of HIV in men. Cochrane Database Syst Rev. 2011;(6):CD007496.

39. New York State Department of Health AIDS Institute. HIV Prophylaxis Following Non-Occupational Exposure. New York, NY: HIV Clinical Resource; 2008. Available at: http://www.hivguidelines.org/clinicalguidelines/post-exposure-prophylaxis/hiv-prophylaxis-following-nonoccupational-exposure-including-sexual-assault/. Accessed July 12, 2012. 
40. Otten RA, Smith DK, Adams DR, et al. Efficacy of postexposure prophylaxis after intravaginal exposure of pig-tailed macaques to a human-derived retrovirus (human immunodeficiency virus type 2). J Virol. 2000;74(20):9771-9775.

41. UK Department of Health. HIV post-exposure prophylaxis: guidance from the UK Chief Medical Officers' Expert Advisory Group on AIDS. London, UK: Department of Health; 2008. Available at: http://webarchive.nationalarchives.gov.uk/20130107105354/ http://www.dh.gov.uk/en/Publicationsandstatistics/Publications/ PublicationsPolicyAndGuidance/DH_088185?ssSourceSiteId=ab. Accessed on February 1, 2014.

42. Roedling S, Reeves I, Copas AJ, et al. Changes in the provision of post-exposure prophylaxis for HIV after sexual exposure following introduction of guidelines and publicity campaigns. Int J STD AIDS 2008;19(4):241-242.

43. Day S, Mears A, Bond K, Kulasegaram R. Post-exposure HIV prophylaxis following sexual exposure: a retrospective audit against recent draft BASHH guidance. Sex Transm Infect. 2006;82(3):236-237.

44. Parkin JM, Murphy M, Anderson J, El-Gadi S, Forster G, Pinching AJ. Tolerability and side-effects of post-exposure prophylaxis for HIV infection. Lancet. 2000;355(9205):722-733.

45. Kahn JO, Martin JN, Roland ME, et al. Feasibility of post-exposure prophylaxis (PEP) against human immunodeficiency virus infection after sexual or injecting drug use exposure: the San Fransisco PEP Study. J Infect Dis. 2001;183(5):707-714.

46. Roland ME, Neilands TB, Krone MR, et al. Seroconversion following nonoccupational postexposure prophylaxis against HIV. Clin Infect Dis. 2005;41(10):1507-1513.

47. Oldenburg CE, Bärnighausen T, Harling G, Mimiaga MJ, Mayer KH. Adherence to post-exposure prophylaxis for non-forcible sexual exposure to HIV: a systematic review and meta-analysis. AIDS Behav. 2014;18(2):217-225

48. Chacko L, Ford N, Sbaiti M, Siddiqui R. Adherence to HIV postexposure prophylaxis in victims of sexual assault: a systematic review and meta-analysis. Sex Transm Infect. 2012;88(5):335-341.

49. Jochimsen EM, Luo CC, Beltrami JF, Respess RA, Schable CA, Cardo DM. Investigations of possible failures of postexposure prophylaxis following occupational exposures to human immunodeficiency virus. Arch Intern Med. 1999;159(19):2361-2363.

50. UK Collaborative Group on HIV Drug Resistance; UK Collaborative HIV Cohort Study; UK Register of HIV Seroconverters. Evidence of a decline in transmitted HIV-1 drug resistance in the United Kingdom. AIDS. 2007;21(8):1035-1039.

51. Vercauteren J, Wensing AM, van de Vijver DA, et al. Transmission of drug-resistant HIV-1 is stabilizing in Europe. J Infect Dis. 2009;200(10): 1503-1508.

52. Gupta RK, Jordan MR, Sultan BJ, et al. Global trends in antiretroviral resistance in treatment-naive individuals with HIV after rollout of antiretroviral treatment in resource-limited settings: a global collaborative study and meta-regression analysis. Lancet. 2012;380(9849): 1250-1258.

53. Poles MA, Elliott J, Vingerhoets J, et al. Despite high concordance, distinct mutational and phenotypic drug resistance profiles in human immunodeficiency virus type 1 RNA are observed in gastrointestinal mucosal biopsy specimens and peripheral blood mononuclear cells compared with plasma. J Infect Dis. 2001;183(1):143-148.

54. Else LJ, Taylor S, Back DJ, Khoo SH. Pharmacokinetics of antiretroviral drugs in anatomical sanctuary sites: the male and female genital tract. Antivir Ther. 2011;16(8):1149-1167.

55. Benn PD, Mercey DE, Brink N, Scott G, Williams IG. Prophylaxis with a nevirapine-containing triple regimen after exposure to HIV-1. Lancet. 2001;357(9257):687-688.

56. Liu AY, Grant RM, Buchbinder SP. Preexposure prophylaxis for HIV: unproven promise and potential pitfalls. JAMA. 2006;296(7): 863-865.

57. Kalichman S. Post-exposure prophylaxis for HIV infection in gay and bisexual men. Implications for the future of HIV prevention. Am J Prevent Med. 1998;15(2):120-127.
58. Donnell D, Mimiaga MJ, Mayer K, Chesney M, Koblin B, Coates T. Use of non-occupational post-exposure prophylaxis does not lead to an increase in high risk sex behaviors in men who have sex with men participating in the EXPLORE trial. AIDS Behav. 2010;14(5):1182-1189.

59. Martin JN, Roland ME, Neilands TB, et al. Use of postexposure prophylaxis against HIV infection following sexual exposure does not lead to increases in high-risk behavior. AIDS. 2004;18(5):787-792.

60. Grant RM, Lama JR, Anderson PL, et al; iPrEx Study Team. Preexposure chemoprophylaxis for HIV prevention in men who have sex with men. N Engl J Med. 2010;363(27):2587-2599.

61. Moyle GJ, DeJesus E, Cahn P, et al; Ziagen Once-Daily in Antiretroviral Combination Therapy (CNA30021) Study Team. Abacavir once or twice daily combined with once-daily lamivudine and efavirenz for the treatment of antiretroviral-naive HIV-infected adults: results of the Ziagen Once Daily in Antiretroviral Combination Study. J Acquir Immune Defic Syndr. 2005;38(4):417-425.

62. Easterbrook PJ, Waters A, Murad S, et al. Epidemiological risk factors for hypersensitivity reactions to abacavir. HIV Med. 2003;4(4):321-324.

63. Baetan J, Donnell D, Ndase P, et al. ARV PrEP for HIV-1 prevention among heterosexual men and women. 19th Conference on Retroviruses and Opportunistic Infections (CROI 2012); March 5-8, 2012; Seattle, WA: abstr 29.

64. Thigpen MC, Kebaabetswe PM, Paxton LA, et al; TDF2 Study Group. Antiretroviral preexposure prophylaxis for heterosexual HIV transmission in Botswana. N Engl J Med. 2012;367(5):423-434.

65. Hendrix C, Minnis A, Guddera V, et al. MTN-001: a Phase 2 cross-over study of daily oral and vaginal TFV in healthy, sexually active women results in significantly different product acceptability and vaginal tissue drug concentrations. 18th Conference on Retroviruses and Opportunistic Infections; February 27-March 2, 2011; Boston, MA: abstr 35LB.

66. Karim SS, Kashuba AD, Werner L, Karim QA. Drug concentrations after topical and oral antiretroviral pre-exposure prophylaxis: implications for HIV prevention in women. Lancet. 2011;378(9787):279-281.

67. Centers for Disease Control and Prevention (CDC). Serious adverse events attributed to nevirapine regimens for postexposure prophylaxis after HIV exposures - worldwide, 1997-2000. MMWR Morb Mortal Wkly Rep. 2001;49(51-52):1153-1156.

68. Intelence Summary of Product Characteristics [webpage on the Internet]. High Wycombe, UK: Janssen-Cilag International NV; 2012. Available at: http://www.medicines.org.uk/emc/medicine/21185/SPC/. Accessed July 12, 2013.

69. Andrew Carr. Safety, Tolerability, and Adherence to Co-formulated Tenofovir-emtricitabine-rilpivirine Used as HIV Nonoccupational Post-exposure Prophylaxis in Men Who Have Sex With Men. (EPEP). Available from: http://clinicaltrials.gov/ct2/show/NCT01715636. NLM identifier: NCT01715636. Accessed February 1, 2014.

70. Janssen-Cilag GmbH. Human Immunodeficiency Virus (HIV) Postexposure Prophylaxis (PEP) With Darunavir/Ritonavir (DRV/r) (PEPDar). Available from: http://clinicaltrials.gov/ct2/show/ NCT01516970. NLM identifier: NCT01516970. Accessed February 1, 2014.

71. Benn P, Fisher M, Kulasegaram R; BASHH; PEPSE Guidelines Writing Group Clinical Effectiveness Group. UK guideline for the use of postexposure prophylaxis for HIV following sexual exposure (2011). Int $J$ STD AIDS. 2011;22(12):695-708.

72. Eron J Jr, Yeni P, Gathe J Jr, et al; KLEAN study team. The KLEAN study of fosamprenavir-ritonavir versus lopinavir-ritonavir, each in combination with abacavir-lamivudine, for initial treatment of HIV infection over 48 weeks: a randomised non-inferiority trial. Lancet. 2006;368(9534):476-482.

73. Diaz-Brito V, León A, Knobel H, et al; DATEMPEP study group. Post-exposure prophylaxis for HIV infection: a clinical trial comparing lopinavir/ritonavir versus atazanavir each with zidovudine/lamivudine. Antivir Ther. 2012;17(2):337-346.

74. Winston A, McAllister J, Amin J, Cooper DA, Carr A. The use of a triple nucleoside-nucleotide regimen for nonoccupational HIV post-exposure prophylaxis. HIV Med. 2005;6(3):191-197. 
75. McAllister J, Read P, McNulty A, Tong WW, Ingersoll A, Carr A. Raltegravir-emtricitabine-tenofovir as HIV nonoccupational postexposure prophylaxis in men who have sex with men: safety, tolerability and adherence. HIV Med. 2014;15(1):13-22.

76. Rockstroh JK, Lennox JL, Dejesus E, et al; STARTMRK Investigators. Long-term treatment with raltegravir or efavirenz combined with tenofovir/emtricitabine for treatment-naive human immunodeficiency virus-1-infected patients: 156-week results from STARTMRK. Clin Infect Dis. 2011;53(8):807-816.

77. Mayer KH, Mimiaga MJ, Gelman M, Grasso C. Raltegravir, tenofovir DF, and emtricitabine for postexposure prophylaxis to prevent the sexual transmission of HIV: safety, tolerability, and adherence. $J$ Acquir Immune Defic Syndr. 2012;59(4):354-359.

78. New York State Department of Health AIDS Institute. HIV prophylaxis following occupational exposure. New York, NY: HIV Clinical Resource; 2012. Available at: http://www.hivguidelines.org/clinicalguidelines/post-exposure-prophylaxis/hiv-prophylaxis-followingoccupational-exposure/. Accessed December 26, 2013.

79. Kenneth H, Mayer MD; Gilead Sciences. HIV Non-Occupational PostExposure Prophylaxis (QUAD). Available from: http://clinicaltrials.gov/ ct2/show/NCT01855867. NLM identifier: NCT01855867. Accessed February 1, 2014.

80. Cooper DA, Heera J, Goodrich J, et al. Maraviroc versus efavirenz, both in combination with zidovudine-lamivudine, for the treatment of antiretroviral-naive subjects with CCR5-tropic HIV-1 infection. J Infect Dis. 2010;201(6):803-813.

81. Hospital Clinic of Barcelona. Study Comparing Two Alternatives of Antiretroviral Therapy as Post-exposure Prophylaxis to HIV-1: FOVIR + EMTRICITABINA + LOPINAVIR/RITONAVIR VS TENOFOVIR + EMTRICITABINA + MARAVIROC (MARAVI-PEP). Available from: http://clinicaltrials.gov/ct2/show/NCT01533272. NLM identifier: NCT01533272. Accessed July 12, 2012.

82. Tolerability and completion of Maraviroc compared to Kaletra ${ }^{\circledR}$ in combination with Truvada ${ }^{\circledR}$ for HIV Post Exposure Prophylaxis. Ref. ISRCTN63350011. Available from: http://www.controlled-trials.com/ ISRCTN63350011/. Accessed July 12, 2012.

83. Evaluating the safety and tolerability of antiretroviral drug regimens used as pre-exposure prophylaxis to prevent HIV infection in men who have sex with men. Available from: at http://clinicaltrials.gov/ct2/show/ NCT01505114. NLM identifier: NCT01505114. Accessed July 12, 2012.

84. Brown KC, Patterson KB, Malone SA, et al. Single and multiple dose pharmacokinetics of maraviroc in saliva, semen, and rectal tissue of healthy HIV-negative men. J Infect Dis. 2011;203(10):1484-1490.

85. Dumond JB, Patterson KB, Pecha AL, et al. Maraviroc concentrates in the cervicovaginal fluid and vaginal tissue of HIV-negative women. $J$ Acquir Immune Defic Syndr. 2009;51(5):546-553.

86. Clavel C, Peytavin G, Tubiana R, et al. Raltegravir concentrations in the genital tract of HIV-1-infected women treated with a raltegravircontaining regimen (DIVA 01 study). Antimicrob Agents Chemother. 2011;55(6):3018-3021

87. Calcagno A, Bonora S, D'Avolio A, et al. Raltegravir penetration in seminal plasma of healthy volunteers. Antimicrob Agents Chemother. 2010;54(6):2744-2745.
88. Kober C, Nixon E, Fisher M, et al. Routine monitoring of bloods for toxicity when using modern post-exposure prophylaxis (PEP) regimens may be unnecessary. Second BHIVA/BASHH Joint Conference; April 20-23, 2010; Manchester, UK; abstr P98.

89. Williams I, Churchill D, Anderson J, et al. British HIV Association guidelines for the treatment of HIV-1-positive adults with antiretroviral therapy 2012. HIV Medicine. 2014;15(Suppl 1):1-85.

90. Truvada film-coated tablets [webpage on the internet]. Gilead Sciences Ltd; 2014. Available from: http://www.medicines.org.uk/ emc/medicine/15826/SPC/Truvada+film-coated+tablets/. Accessed July 17, 2014.

91. Viread $245 \mathrm{mg}$ film-coated tablets [webpage on the internet]. Gilead Sciences Ltd; 2014. Available from: http://www.medicines.org.uk/emc/ medicine/9008/SPC/Viread $+245+\mathrm{mg}+$ film-coated + tablets/. Accessed July 17, 2014.

92. Smith DK, Grohskopf LA, Black RJ, et al; US Department of Health and Human Services. Antiretroviral postexposure prophylaxis after sexual, injection-drug use, or other nonoccupational exposure to HIV in the United States: recommendations from the US Department of Health and Human Services. MMWR Recomm Rep. 2005;54(RR2): $1-20$.

93. Snell L, Edwards SG, Benn PD. Potential impact of updated UK guidelines for use of post exposure prophylaxis following sexual exposure in a London sexual health service. BASHH-ASTDA 4th Joint Meeting; June 27-29, 2012; Brighton, UK; abstr P20.

94. European AIDS Clinical Society (EACS). Guidelines for the Clinical Management and Treatment of HIV Infected Adults in Europe (v7). Brussels, Belgium: European AIDS Clinical Society; 2013. Available from: http://www.eacsociety.org/Portals/0/Guidelines_Online_131014. pdf. Accessed January 2, 2014.

95. Australian Society of HIV Medicine (ASHM). Post-Exposure Prophylaxis after Non-Occupational and Occupational Exposure to HIV: National Guidelines. Surry Hills, Australia: Australian Society of HIV Medicine; 2013. Available from: http://www.ashm.org.au/pepguidelines/NPEPPEPGuidelinesDec2013.pdf. Accessed January 1, 2014.

96. Joshi M, Basra A, McCormick C, Webb H, Pakianathan M. Postexposure prophylaxis after sexual exposure (PEPSE) awareness in an HIV-positive cohort. Int J STD AIDS. 2014;25(1):67-69.

97. Rodríguez AE, Castel AD, Parish CL, et al. HIV medical providers' perceptions of the use of antiretroviral therapy as nonoccupational postexposure prophylaxis in 2 major metropolitan areas. $J$ Acquir Immune Defic Syndr. 2013;64 Suppl 1:S68-S79.

98. Hankins CA, de Zalduondo BO. Combination prevention: a deeper understanding of effective HIV prevention. AIDS. 2010;24(Suppl 4): S70-S80.

99. Paxton LA, Hope T, Jaffe HW. Pre-exposure prophylaxis for HIV infection: what if it works? Lancet. 2007;370(9581):89-93.

100. Joint United Nations Programme on HIV/AIDS (UNAIDS). Global report. Geneva, Switzerland: UNAIDS; 2010. Available at: http://www. unaids.org/globalreport/Global_report.htm. Accessed February 1, 2014.
HIV/AIDS - Research and Palliative Care

\section{Publish your work in this journal}

HIV/AIDS - Research and Palliative Care is an international, peerreviewed open-access journal focusing on advances in research in HIV, its clinical progression and management options including antiviral treatment, palliative care and public healthcare policies to control viral spread. The journal welcomes original research, basic science,

\section{Dovepress}

clinical \& epidemiological studies, reviews \& evaluations, expert opinion \& commentary, case reports \& extended reports. The manuscript management system is completely online and includes a very quick and fair peer-review system. Visit http://www.dovepress.com/ testimonials.php to read real quotes from published authors. 